\title{
HARMONIZATION OF TECHNICAL DEMANDS TO PAINT COATINGS AS A COMPONENT OF COMPETITIVENESS INCREASE ON THE INTERNATIONAL MARKET
}

\author{
${ }^{1}$ Veniamin BOLDYREV, ${ }^{2}$ Vladimir MEN'SHIKOV, ${ }^{3}$ Flura IL'DARKHANOVA, \\ ${ }^{3}$ Valentina PUCHKOVA, ${ }^{2}$ Daria STRAPOLOVA \\ 1Bauman Moscow State Technical University, Moscow, Russia, boldyrev.v.s@bmstu.ru \\ ${ }^{2}$ D. Mendeleev State Technical University, Moscow, Russia,vm uti@muctr.ru \\ ${ }^{3}$ Scientific Production Association «Lakokraspokrytiye», Khotkovo, Moscow region, Russia, mail@npolkp.ru
}

https://doi.org/10.37904/metal.2020.3538

\begin{abstract}
The specific feature of modern Russian paintwork material (PWM) market is an import share rise along with foreign manufactures extensive expansion. Russian market range of PWM contents above 3000 items, considering both PWM being used in household and foreign products. Import products are $25-30 \%$ of Russian PWM market volume. High level of rivalry, marketing battle between foreign and domestic manufactures is common for it. Major PWM exporting countries in Russia are: German (14\% of total amount), Finland (11\%), Belarus (9,7\%), Estonian (9\%), USA(8,9\%), Korea (7,5\%), Lithuania (7\%). According to «Symbol Marketing» agency data, Tikkurila (Finland), AkzoNobel (Sweden), Meffest AG (German), PPG-Helios (Italy-Slovenia), BASF (German), Jobi (German), Teknos (Finland), Marshall (Turkey), DuPont (USA) lead among the manufacturing companies exporting their PWM in Russia. The main domestic PWM competitiveness rise condition is establishment of common quality, endurance, ecological safety and evaluating methods standards accepted as in Russia so in other countries. This scientific research made for PWM manufacturers and consumers solves International Organization for Standardization (ISO) and Russian National Standart (GOST) interaction problem in order to standardize Russian PWM output and increase its competitiveness at the international market.
\end{abstract}

Keywords: Paintwork materials (PWM), corrosion-resistance, paint technologies, ISO, GOST

\section{INTRODUCTION}

Paint coating (PC) endurance requirements and its evaluating methods are standardized in Russia with Russian National Standart: GOST 9.401-91 "Paint coating. Common demands and accelerated environmental resistance tests methods". Standard has been elaborated in the second half of 1980-s and nowadays it completely corresponds to Russian paintwork industry condition. Range of GOST recommended PWM and PC has been extended with alkyd and modified alkyd, epoxy and water-dispersion PWM and consists above 1000 items. Nowadays the number of PWM on the Russian market is above 3000 , considering household PWM and foreign-made products. It is impossible to extend range of GOST recommended PC more. In conditions of high market rivalry, it is necessary to accept new requirements on PWM and PC and adjust it to ISO compulsory.

\section{EXPERIMENTAL PART}

GOST 9.401-91 PC operating conditions requirements are connected with GOST 15150-69 product realization categories by environmental exposure impact. It includes temperature and humidity, environmental corrosiveness rate and category of product location (open-air, awning, room). Developing accelerated 
techniques, we have considered environmental impact (temperature, humidity, solar radiation) and the corrosive agents volume in the environment [1].

ISO 12944:1998 "Paints and varnishes. Corrosion protection of steel structures by protective paint systems" is the foreign international standard, rationing metal corrosion protection demands. The standard categorizes environment according to speed of metal weight or thickness loss due to electrochemical and chemical corrosion. Meanwhile, the PC lifespan is defined by theoretical protective paintwork system endurance being counted until the first overhaul [2-4]. Basing on this categorizing, the methods of accelerated tests and its endurance have been formed so as to define the PC lifespan.

In this scientific research the author's team opinion about aforementioned standards interaction is shown. It is practically relevant to PWM manufacturers and consumers. Many industries are already using ISO 12944:1998. E.g., Russian and foreign standards requirements are used in industry road guiding document IRG 218.4.002-2009, in which rules of structures, bridge connections, fences and road signs, being exploited on Russian roads, corrosion protection are written, and they are also used in anticorrosion protection of tanks guiding document GD-05.00-45.21.30-KHT-005-1-05.

To our mind, interaction between GOST 9.104-79, GOST 15150-69 and ISO 12944:1998 in terms of environmental factors interplay can be represented as it shown in Table 1.

Table 1 Terms of products with GOST 9.104 coating exploitation depending on GOST 15150 atmosphere types and ISO 12944-2 atmospheric corrosion activeness category

\begin{tabular}{|c|c|c|c|c|c|c|}
\hline \multirow{2}{*}{$\begin{array}{c}\text { GOST } 15150 \\
\text { atmospheric type } \\
\text { (designation and } \\
\text { name) }\end{array}$} & \multicolumn{6}{|c|}{ Designation and name of ISO 12944-2 exploitation conditions } \\
\hline & $\begin{array}{c}\text { C1 } \\
\text { very } \\
\text { low }\end{array}$ & $\begin{array}{l}\text { C2 } \\
\text { low }\end{array}$ & $\begin{array}{c}\text { C3 } \\
\text { medium }\end{array}$ & $\begin{array}{c}\text { C4 } \\
\text { high }\end{array}$ & $\begin{array}{c}\text { C5-1 very } \\
\text { high } \\
\text { (industrial) }\end{array}$ & $\begin{array}{c}\text { C5-M very } \\
\text { high } \\
\text { (marine) }\end{array}$ \\
\hline I conditionally clean & $\begin{array}{l}\text { N3, } \\
\text { NF3, } \\
\text { NF4 }\end{array}$ & $\begin{array}{l}\text { N1, N2, NF1, } \\
\text { NF2, T1, T2, } \\
\text { T3, U4, MU4, } \\
\text { W4 }\end{array}$ & $\begin{array}{c}\text { N1, N2, NF1, T1, } \\
\text { T2, U1, U2 }\end{array}$ & - & - & - \\
\hline II industrial & $\begin{array}{c}\text { N3, } \\
\text { NF3, } \\
\text { T3 }\end{array}$ & $\begin{array}{c}\text { N2, N3, NF1, } \\
\text { NF2, NF3, } \\
\text { T1, T2, T3 }\end{array}$ & $\begin{array}{c}\mathrm{N} 1, \mathrm{~N} 2, \mathrm{~N} 3, \\
\mathrm{NF} 1, \mathrm{NF} 2, \mathrm{NF} 3 \\
\mathrm{~T} 1, \mathrm{~T} 2, \mathrm{~T} 3, \mathrm{U} 1 \\
\mathrm{U} 2\end{array}$ & $\begin{array}{c}\text { N1, N2, } \\
\text { NF1, NF2, } \\
\text { T1, T2, U1, } \\
\text { U2 }\end{array}$ & $\mathrm{N} 1, \mathrm{~N} 2, \mathrm{~T} 1, \mathrm{~T} 2$ & - \\
\hline III marine & - & - & T3, MU3, W3 & $\begin{array}{l}\text { T3, MU3, } \\
\text { W3 }\end{array}$ & - & $\begin{array}{c}\text { T1, T2, } \\
\text { MU1, MU2, } \\
\text { W1, W2 }\end{array}$ \\
\hline IV seaside-industrial & - & - & T3 & - & - & - \\
\hline
\end{tabular}

In compliance with GOST 9.401-91 requirements, a coating lifespan in exploitation conditions of temperate and cold climate should be above 2 years, in exploitation conditions of tropical, marine climate and also general climatic and all-climatic modifications it should be above 1 year. Obviously, it is not enough to compete with foreign PWM. In ISO 12944:1998, a lifespan equal 2-5 years is considered as a short one. Almost $90 \%$ of GOST 9.401-91 branded range has short lifespan. Less than 10\% of GOST 9.401-91 branded range has an average lifespan (5-15 years, according to ISO 12944:1998) and only 1-2\% has a long lifespan (above 15 years, according to ISO 12944:1998). We consider, that new PWM brands with a short lifespan should be developed only to replace outdated ones with taking the last out of the stock. Creating recommended PWM range with medium or long lifespan is necessary. Only PWM with lifespan of 10-15 years can compete with foreign PWM brands. It is known, that the accelerated tests, which are needed to confirm given lifespan, take 3-4 months and demand an expensive testing equipment, qualified staff and a round-the-clock monitoring of 
experiment process. That is why we ran some preliminary tests to make accelerated tests based on ISO 12944 expedient (results are shown in Table 2).

Table 2 Preliminary GOST 9.104 and ISO 12944-2 PWM tests (comparative analysis)

\begin{tabular}{|c|c|c|c|c|c|c|c|}
\hline \multirow{2}{*}{ 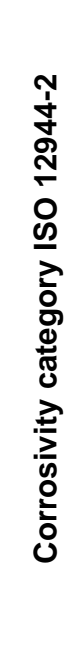 } & \multirow{2}{*}{ 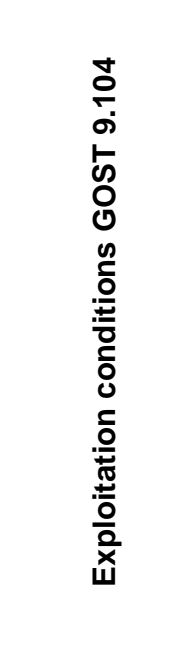 } & \multirow{2}{*}{ 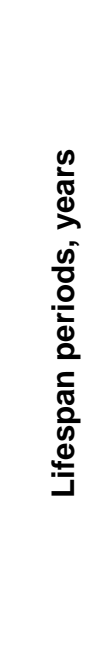 } & 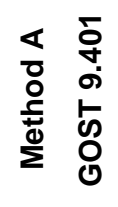 & 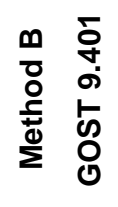 & $\begin{array}{ll}0 & \bar{q} \\
0 & \sigma \\
0 & \circ \\
\frac{c}{0} & - \\
\Sigma & 0\end{array}$ & 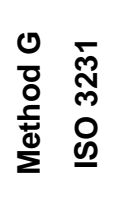 & 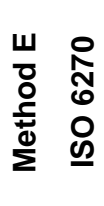 \\
\hline & & & 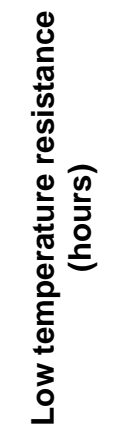 &  &  & 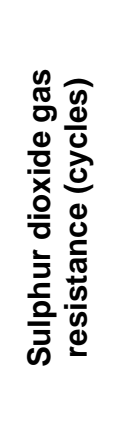 &  \\
\hline \multirow{6}{*}{$\mathrm{C} 2$} & \multirow{3}{*}{$\mathrm{N} 1, \mathrm{~N} 2, \mathrm{~N} 3$} & $2-5$ & - & - & - & - & 48 \\
\hline & & $5-15$ & - & - & - & - & 48 \\
\hline & & $>15$ & - & - & - & - & 120 \\
\hline & \multirow{3}{*}{$\begin{array}{c}\mathrm{NF} 1, \mathrm{NF} 2 \\
\mathrm{NF3}\end{array}$} & $2-5$ & 2 & - & - & - & 48 \\
\hline & & $5-15$ & 2 & - & - & - & 48 \\
\hline & & $>15$ & 2 & - & - & - & 120 \\
\hline \multirow{6}{*}{ C3 } & \multirow{3}{*}{$\mathrm{N} 1, \mathrm{~N} 2, \mathrm{~N} 3$} & $2-5$ & - & 120 & - & - & 48 \\
\hline & & $5-15$ & - & 240 & - & - & 120 \\
\hline & & $>15$ & - & 480 & - & - & 240 \\
\hline & \multirow{3}{*}{$\begin{array}{l}\text { NF1 NF2, } \\
\text { NF3 }\end{array}$} & $2-5$ & 2 & 120 & - & - & 48 \\
\hline & & $5-15$ & 2 & 240 & - & - & 120 \\
\hline & & $>15$ & 2 & 480 & - & - & 240 \\
\hline \multirow{6}{*}{$\mathrm{C} 4$} & \multirow{3}{*}{ T1 } & $2-5$ & - & 240 & 100 & - & 120 \\
\hline & & $5-15$ & - & 480 & 100 & - & 240 \\
\hline & & $>15$ & - & 720 & 100 & - & 480 \\
\hline & \multirow{3}{*}{ T2, T3 } & $2-5$ & - & 240 & - & - & 120 \\
\hline & & $5-15$ & - & 480 & - & - & 240 \\
\hline & & $>15$ & - & 720 & - & - & 480 \\
\hline \multirow{6}{*}{ C5-1 } & \multirow{3}{*}{ T1 } & $2-5$ & - & 480 & 100 & 10 & 240 \\
\hline & & $5-15$ & - & 720 & 100 & 20 & 480 \\
\hline & & $>15$ & - & 1440 & 100 & 30 & 720 \\
\hline & \multirow{3}{*}{ T2, T3 } & $2-5$ & - & 480 & - & 10 & 240 \\
\hline & & $5-15$ & - & 720 & - & 20 & 480 \\
\hline & & $>15$ & - & 1440 & - & 30 & 720 \\
\hline
\end{tabular}




\begin{tabular}{|c|c|c|c|c|c|c|c|}
\hline \multirow{6}{*}{ C5-1 } & \multirow{3}{*}{ U1 } & $2-5$ & 2 & 480 & 100 & 10 & 240 \\
\hline & & $5-15$ & 2 & 720 & 100 & 20 & 480 \\
\hline & & $>15$ & 2 & 1440 & 100 & 30 & 720 \\
\hline & \multirow{3}{*}{ U2 } & $2-5$ & 2 & 480 & - & 10 & 240 \\
\hline & & $5-15$ & 2 & 720 & - & 20 & 480 \\
\hline & & $>15$ & 2 & 1440 & - & 30 & 720 \\
\hline \multirow{9}{*}{ C5-M } & \multirow{3}{*}{$\begin{array}{c}\text { MU1, MU2, } \\
\text { MU3 }\end{array}$} & $2-5$ & - & 480 & - & - & 480 \\
\hline & & 5-15 & - & 720 & - & - & 720 \\
\hline & & $>15$ & - & 1440 & - & - & 1440 \\
\hline & \multirow{3}{*}{ W1 } & $2-5$ & 2 & 480 & 100 & 10 & 480 \\
\hline & & 5-15 & 2 & 720 & 100 & 20 & 720 \\
\hline & & $>15$ & 2 & 1440 & 100 & 30 & 1440 \\
\hline & \multirow{3}{*}{ W2, W3 } & $2-5$ & 2 & 480 & - & 10 & 480 \\
\hline & & 5-15 & 2 & 720 & - & 20 & 720 \\
\hline & & $>15$ & 2 & 1440 & - & 30 & 1440 \\
\hline
\end{tabular}

Defining PC lifespan, it is inexpedient to be guided by ISO 12944:1998 only. The standard allows too wide interval of PC lifetime, but does not consider environmental factors, solar radiation, that cause photo-oxidative degradation of film-former, changing photochemical activity of pigments and fillers, processes of structure formation, aging and irreversible properties changes in PC [5-7]. In addition, influence of temperature fluctuations is not considered, especially swings with passing through $0{ }^{\circ} \mathrm{C}$, which could cause micro- and macrocrackings as a result of moisture sorption, desorption and its freezing in PC. Prolonged low temperature exposure, typical for Russian Federation's areas with temperate and cold climate, also is not considered in the standard. According to NPO «Varnish-and-Coatment» data, adhesion declines in PC film because of inside tensions after prolonged low temperature exposure, as a result, PC can crack and peel off. These kinds of destruction are not typical for PC exploited at the area of Western European and other countries with temperate climate [8-10]. Moreover, ISO 12944:1998 has impact only on PC covering steel and galvanized steel. According to this standard, some tests are unacceptable for water-dispersion PWM. The standard does not include powder PC, PC made of thermosetting enamels or hot-drying enamels, PC with more than $2 \mathrm{~mm}$ thickness, PC used in tank cladding [1]. However, it is necessary to use with special carefulness the results got during researches and tests demanded by the standard. Sometimes the test results make give up efficient protective PC, because it does not stand the tests. In order to determine PC lifespan, ISO 12944:1998 notes the necessity of additional cyclic tests applying UV radiation and temperature fluctuations.

\section{RESULTS AND ITS DISCUSSION}

It is considered premature for lots of paint and varnish factories to shift to ISO 12944:1998 in determining operating conditions and PC lifespan. Despite the standard is widely used in Europe to determine PC lifespan, there are quite a few publications evidencing low correlation between natural and accelerated tests. According to «Jortun» firm data, in determining real PC lifespan there are next correlation coefficients used in Holland: natural tests $-0,85$; water resistance tests $-0,45$; salt fog tests $-0,5$; cyclic tests $-0,65$. Salt fog tests have high correlation in a case of metal surfaces, but there is no satisfactory correlation detected in a case of organic surface. There are different corrosion products formed in normal natural conditions (with the exception of marine settings and chemical factory's conditions), than during salt fog tests. According to NPO «Varnish-andCoatment» research data, the salt fog test method (the spreading of corrosion from an incision) has proved itself for evaluating the quality of a surface preparation among water-borne, electrophoresis and inhibited 
PWM, i.e. during evaluating the character of interactions between PC and painted surface, but not its barrier properties. European colleagues have similar conclusions.

There are international and national standards used in international practice. For instance, ISO 11997-1:2005 establishes the methods of accelerated tests, in which PC are exposed to cyclic impact of salt fog, are dried and moisturized. The researches show, that tests held by mentioned standard have high correlation with results of natural tests. Moreover, one of the methods has high correlation with results of exploitation PC on automobiles in Japan and USA, another one - in Europe, the third, according to Great Britain data - for waterdispersion paints.

Russian Federation climate, unlike European, Great Britain and others, is characterized as harsh continental, that is expressed by: high daily and annual temperature fluctuations, prolonged frosts in wintertime, rapid daily fluctuations of air temperature in spring and summer, short hot summer. Furthermore, 2/3 of Russian Federation area belongs to cold climate zone, where in winter temperature can decrease until $(-45)-(-60)^{\circ} \mathrm{C}$.

We developed cyclic tests for temperate climate basing on results of natural PC tests held on climate stations in Khotkovo (Moscow region), Moscow, Zvenigorod, Skovorodino (Amur region), Letnany (Czech Republic), Orgovan (Hungary); for cold climate - in Yakutsk, Norilsk, Magadan, Murmansk; for tropical climate - in Yemen, Havana, Vietnam, Georgia, Uzbekistan; for marine climate - on ships passing through water areas of tropical seas and Arctic Ocean. GOST 9.401-91 tests methodologies have high correlation with natural tests results. The forecasting mistake is $\pm 10 \%$. Using mostly ISO standards to determine PC lifespan is inexpedient because of climate features of Russian Federation. Besides, comparing with foreign methods, GOST 9.40191 accelerated tests modes are stricter due to increased intensity and frequency of environmental factors impact, applied without distorting the character of physical-chemical processes, occurred in PC film. Because of that, accelerated tests could be successfully used for evaluating PC durability both for domestic market and for export. Using accelerating coefficients for different exploitation conditions, it is possible to forecast PC lifespan with sufficient reliability.

It is expedient to accept ISO 12944-5:1998 demands as anticorrosion properties evaluation criteria for PC with long life cycle. According to this standard, requests for PC are tests results, basing on which is defined the PC applicability for anticorrosion protection. PC should be being tested until reaching 2-3 (S2-S3) degree of bloating (bubbles), cracking and peeling and Ri corrosion according to ISO 4628-3:2003. This condition according to GOST 9.407-84 is equal generalized score 3 (there are allowed visible destruction of outer layer till $5 \%$ of the surface and corrosion till $1 \%$ of the surface with corrosion damage size till $0,5-1 \mathrm{~mm}$ ). Such PC faults requires local repairing painting. Full recovery (repainting) of protective coating is realized in case of decaying up to $20 \%$ of product total surface area with corrosion degree K4-K5.

PC lifespan has high economic and ecological significance [2]. Efficient protection of industrial objects provides resource saving, prolonging their lifespan and exploitation period. There are data showing, that inefficient anticorrosion protection leads to losing e.g. 25 millions $€$ per year in German. It is worth saying that in a case of annual tightening of environmental legislation in Europe ecological integrity of PWM becomes a question of their competitiveness on market. PWM volatile components emission limitations are being imposed. The sphere of using pigments, based on plumbum and chromium (IV), is shrinking. The number of countries forbids using of ethylene glycol in pigment pastes.

Nowadays, less than $15 \%$ of PWM made in Russia completely match directive demands accepted among European Union countries.

Tightening of ecological safety requests for produced PWM and their detrimental impact on environment decrease establish additional tasks to PWM manufacturers. E.g. PC intended to do interior building work must not contain mercury, arsenic, lead, chromium (IV), cadmium and their compounds. PWM must not contain benzene, pyrobenzene, chlorinated hydrocarbons and methanol. 
Along with main designation PWM demands and regulatory documents registration, their lifespan and ecological safety confirmation, requirements of increasing PC lifespan are made. Nowadays, at Russian market the share of PWM with prolonged lifetime, being able to compete in technical indicators with foreign analogs, has been raised.

\section{CONCLUSION}

Thus, nowadays an urgency to revise GOST 9.401-91 has appeared as we should take into account modern ecological, economic and exploitation demands to PC. In order to increase competitiveness of domestic PWM at the international market, it is necessary to form a range of PC with medium (5-15 years) and long (more than 15 years) lifespan, which would satisfy requests of European and international standards. To actualize its standards NPO «Varnish-and-Coatment» is going to significantly change branded range of PWM and align it to modern demands to be able to compete with foreign brands.

\section{REFERENCES}

[1] NELUB, V.A., GORBERG, B.L., GRISHIN, M.V., SARVADII, S.R., SHUB, B.R., BERLIN, A.A., MALYSHEVA, G.V. Properties and technology for applying metal coating to carbon tape. Fibre Chemistry. 2019, vol. 50, no. 6, pp. 524-527.

[2] BOGOMOLOV, B.B., ZUBAREV, A.M., MESHALKIN, V.P., MEN'SHIKOV, V.V., BOLDYREV, V.S. Intelligent logical information algorithm for choosing energy- and resource-efficient chemical technologies. Theoretical Foundation of Chemical Engineering. 2019, vol. 53, no. 5, pp. 709-718.

[3] SHISHLOV, A.V., SAGATELYAN, H.R., SHASHURIN, V.D. Development and implementation of methods and means for achieving a uniform functional coating thickness. Russian Metallurgy (Metall). 2017, vol. 217, no. 13, pp. 1165-1169.

[4] KOLESNIKOV, A.G., CHEREPANOV, D.S., CHEKULAEV, A.V., MIRONOVA, M.O. Analysis of drive mechanisms for the working stand in periodic cold-rolled pipe mills. Metallurgist. 2018, vol. 61, no. 11-12, pp. 1102-1107.

[5] KOVALEV, A.A., KUZNETSOV, N.N. Cavitation fracture of typical materials used in hydraulic machines and units. Russian Metallurgy (Metall). 2017, vol. 217, no. 13, pp. 1202-1206.

[6] MESHALKIN, V.P., ABRASHOV, A.A., VAGRAMYAN, T.A., GRIGORYAN, N.S. Development of composition and study of properties of new high-efficiency silicon-containing protective conversion coating on zing-plated surfaces. Doklady Chemistry, 2017, vol. 475, no. 2, pp. 196-199.

[7] LOMAKINA, G.Yu. Role of biofilms in microbiologically influenced corrosion of metals. Herald of Bauman Moscow State Technical University, 2020, no. 1, pp. 100-125.

[8] MESHALKIN, V.P., ABRASHOV, A.A., VAGRAMYAN, T.A., GRIGORYAN, N.S., UTOCHKINA, D.S. Development of composition and investigation pf properties of new, environmentally friendly molybdenumcontaining decorative protective conversion coating on zing-plated surfaces. Doklady Chemistry, 2017, vol. 480, no. 2, pp. 132-135.

[9] VINOKUROV, E.G., MESHALKIN, V.P., VASILENKO, E.A., NEYMYATULLINA, K.A., BURUKHINA, T.F., BONDAR, V.V. System analysis of the efficiency and competitiveness of chroming technologies. Theoretical Foundation of Chemical Engineering, 2016, vol. 50, no. 5, pp. 730-738.

[10] FADEEV, G.N., BOLDYREV, V.S., AVERINA, Y.M., BOGATOV, N.A. Metal surface treatment in a low-frequency exposure field. Tsvetnye Metally, 2019, no. 10, pp. 73-77. 